\title{
Ionizing Radiation Changes the Electronic Properties of Melanin and Enhances the Growth of Melanized Fungi
}

\author{
Ekaterina Dadachova ${ }^{1,2 *}$, Ruth A. Bryan ${ }^{1}$, Xianchun Huang ${ }^{1}$, Tiffany Moadel ${ }^{1}$, Andrew D. Schweitzer ${ }^{1}$, Philip Aisen ${ }^{3}$, Joshua D. Nosanchuk ${ }^{2,4}$,
} Arturo Casadevall ${ }^{2,4}$

1 Department of Nuclear Medicine, Albert Einstein College of Medicine, Bronx, New York, United States of America, 2 Microbiology and Immunology, Albert Einstein College of Medicine, Bronx, New York, United States of America, 3 Physiology and Biophysics, Albert Einstein College of Medicine, Bronx, New York, United States of America, 4 Medicine, Albert Einstein College of Medicine, Albert Einstein College of Medicine, Bronx, New York, United States of America

Background. Melanin pigments are ubiquitous in nature. Melanized microorganisms are often the dominating species in certain extreme environments, such as soils contaminated with radionuclides, suggesting that the presence of melanin is beneficial in their life cycle. We hypothesized that ionizing radiation could change the electronic properties of melanin and might enhance the growth of melanized microorganisms. Methodology/Principal Findings. lonizing irradiation changed the electron spin resonance (ESR) signal of melanin, consistent with changes in electronic structure. Irradiated melanin manifested a 4-fold increase in its capacity to reduce NADH relative to non-irradiated melanin. HPLC analysis of melanin from fungi grown on different substrates revealed chemical complexity, dependence of melanin composition on the growth substrate and possible influence of melanin composition on its interaction with ionizing radiation. XTT/MTT assays showed increased metabolic activity of melanized $C$. neoformans cells relative to non-melanized cells, and exposure to ionizing radiation enhanced the electron-transfer properties of melanin in melanized cells. Melanized Wangiella dermatitidis and Cryptococcus neoformans cells exposed to ionizing radiation approximately $\mathbf{5 0 0}$ times higher than background grew significantly faster as indicated by higher CFUs, more dry weight biomass and 3 -fold greater incorporation of ${ }^{14} \mathrm{C}$-acetate than non-irradiated melanized cells or irradiated albino mutants. In addition, radiation enhanced the growth of melanized Cladosporium sphaerospermum cells under limited nutrients conditions. Conclusions/Significance. Exposure of melanin to ionizing radiation, and possibly other forms of electromagnetic radiation, changes its electronic properties. Melanized fungal cells manifested increased growth relative to non-melanized cells after exposure to ionizing radiation, raising intriguing questions about a potential role for melanin in energy capture and utilization.

Citation: Dadachova E, Bryan RA, Huang X, Moadel T, Schweitzer AD, et al (2007) lonizing Radiation Changes the Electronic Properties of Melanin and Enhances the Growth of Melanized Fungi. PLoS ONE 2(5): e457. doi:10.1371/journal.pone.0000457

\section{INTRODUCTION}

The term "melanin" originates from melanos - a Greek word for black. Melanin is a high molecular weight pigment, ubiquitous in nature, with a variety of biological functions [1]. Many fungi constitutively synthesize melanin [2], which is likely to confer a survival advantage in the environment [3] by protecting against UV and solar radiation [reviewed in 4]. Melanized microorganisms inhabit some remarkably extreme environments including high altitude, Arctic and Antarctic regions [5]. Most dramatically, melanized fungal species colonize the walls of the highly radioactive damaged reactor at Chernobyl [6] and surrounding soils [7]. These findings, and the laboratory observations of the resistance of melanized fungi to ionizing radiation [8,9], suggest a role for this pigment in radioprotection.

The role of melanin in microorganisms living in high electromagnetic radiation fluxes is even more intriguing when the pigment is considered from a paleobiological perspective. Many fungal fossils appear to be melanized [10,11]. Melanized fungal spores are common in the sediment layers of the early Cretaceous period when many species of animals and plants died out which coincides with the Earth's crossing the "magnetic zero" resulting in the loss of its : "shield" against cosmic radiation [12]. Additionally, radiation from a putative passing star called Nemesis has been suggested as a cause of extinction events [13]. The proliferation of melanotic fungi may even have contributed to the mass extinctions at the end of Cretaceous period [14]. A symbiotic association of plants and a melanotic fungus that allows for extreme thermotolerance has been attributed to heat dissipating properties of melanin [15]. Melanotic fungi inhabit the extra- ordinarly harsh climate of Antarctica [5]. Hence, melanins are ancient pigments that have probably been selected because they enhance the survival of melanized fungi in diverse environments and, perhaps incidentally, in various hosts. The emergence of melanin as a non-specific bioprotective material may be a result of the relative ease with which these complicated aromatic structures can be synthesized from a great variety of precursors [2,4,5,16-23].

Despite the high prevalence of melanotic microorganisms in radioactive environments, it is unlikely that melanin is synthesized solely for the purposes of protection (shielding) from ionizing radiation. For example, in high elevation regions inhabited by melanotic fungi the background radiation levels are approximately 500-1,000 higher than at sea level, which amounts to a dose of 0.50-1.0 Gy/year. Since the overwhelming majority of fungi,

Academic Editor: Julian Rutherford, Newcastle University, United Kingdom

Received January 21, 2007; Accepted April 24, 2007; Published May 23, 2007

Copyright: (c) 2007 Dadachova et al. This is an open-access article distributed under the terms of the Creative Commons Attribution License, which permits unrestricted use, distribution, and reproduction in any medium, provided the original author and source are credited.

Funding: The research was partially supported by NIH grant Al52733 (AC and JN). Funders played no role in this study.

Competing Interests: The authors have declared that no competing interests exist.

* To whom correspondence should be addressed. E-mail: edadacho@aecom.yu. edu 
melanized or not, can withstand doses up to $1.7 \times 10^{4}$ Gy [9], there is no apparent requirement for melanin as a radiation protector. On the other hand, biological pigments play a major role in photosynthesis by converting the energy of light into chemical energy. Chlorophylls and carotenoids absorb light of certain wavelengths and help convert photonic energy into chemical energy during photosynthesis. Given that melanins can absorb visible and UV light of all wavelengths [16], we hypothesized that exposure to ionizing radiation would change the electronic properties of melanin and affect the growth of melanized microorganisms. Here we report the results of physico-chemical investigations of melanin electronic properties after radiation exposure and the enhanced growth of melanized fungi under conditions of radiation flux.

\section{RESULTS}

\section{Chemical composition and paramagnetic properties of melanin influence its interaction with ionizing \\ radiation}

Our previous work with the human pathogenic fungus Cryptococcocus neoformans [24] as well as this study showed that fungal melanin is concentrated in the cell wall and assembled into multiple concentric layers of approximately $100 \mathrm{~nm}$ in thickness consisting of closely packed smaller particles [25]. Melanin particles of hollow spherical shape can be isolated from melanized cells by digestion in concentrated acid and have been dubbed "ghosts" because they retain the shape and dimensions of the parent cell. Fig. 1 shows the melanin ghosts of two fungal species investigated in this work - C. neoformans which becomes melanized when grown in presence of a melanin pre-cursor such as L-dopa (3,4dihydroxyphenylalanin) (Fig. 1a) and Cladosporium sphaerospermum - an intrinsically melanized fungus found in abundance at the site of nuclear accident in Chernobyl which produces melanin in the variety of growth conditions - from nutrient rich medium to almost complete starvation (Fig. 1b-e).

In order to investigate the influence of the chemical composition of melanin on its interaction with ionizing radiation, we performed high performance liquid chromatography (HPLC) analysis of melanins from the different fungi used in this study. It must be noted that the structures of both synthetic [17] and natural melanins including fungal melanin are still poorly understood. It is generally accepted, however, that there are two major types of melanin: eumelanin and pheomelanin. Eumelanin is a dark-brown to black pigment composed of 5,6-dihydroxyindole (DHI) and 5,6- a)

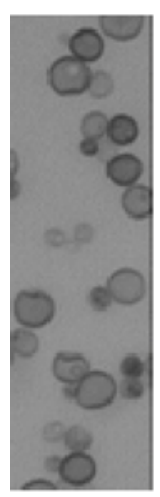

b)

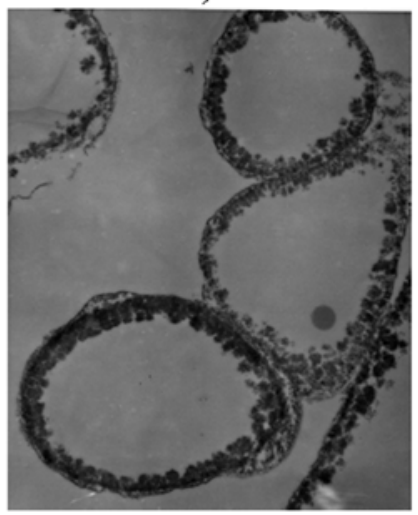

c)

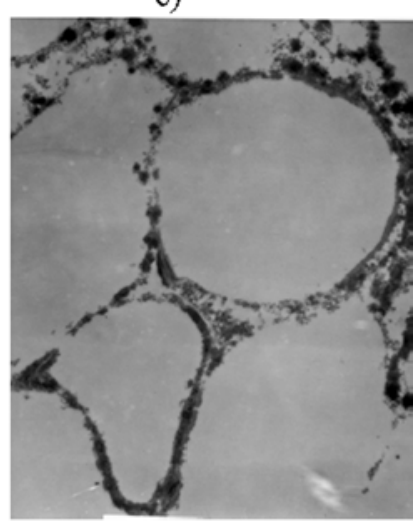

d)

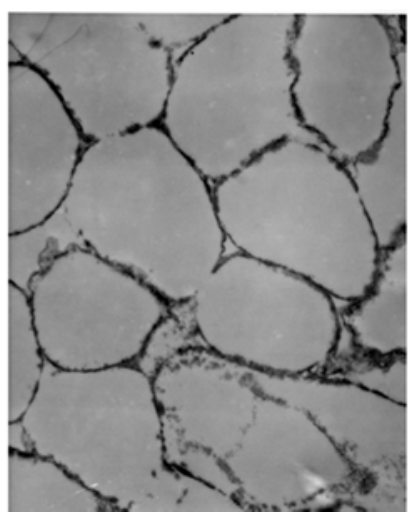

e)

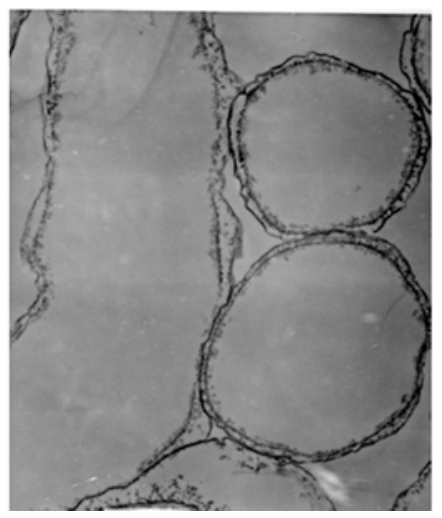

Figure 1. Microscopic images of melanized fungal cells: a) light microscopy image of $C$. neoformans melanin "ghosts"; (b-e) TEM images of $C$. sphaerospermum "ghosts" derived from cells grown on nutrient rich or nutrient-deficient media: b) potato dextrose agar; c) Sabaroud dextrose agar; d) water agar with casein; e) water agar with dextrose. Original magnification: light microscopy image - X 1,000; TEM images - X 13,000. doi:10.1371/journal.pone.0000457.g001 
dihydroxyindole-2-carboxylic acid (DHICA) monomer units with 6-9\% nitrogen and $0-1 \%$ sulfur $[18,19]$ (Fig. 2a). In contrast, pheomelanin is a reddish-brown pigment composed of benzothiazine monomer units with $8-11 \%$ nitrogen and $9-12 \%$ sulfur [18,19] (Fig. 2b). When subjected to acidic permanganate oxidation, DHI converts into pyrrole-2,3-dicarboxylic acid (PDCA); DHICA - into pyrrole-2,3,5-tricarboxylic acid (PTCA); and pheomelanin oxidation results in 1,3-thiazole-2,4,5-tricarboxylic acid (TTCA) and 1,3-thiazole-4,5-dicarboxylic acid (TDCA) $[18,19]$. We have previously shown that permanganate-oxidized melanin from C. neoformans is amenable to HPLC analysis [20,21]. In this study we performed semi-quantitative assessment of the number of structural subunits of C. neoformans melanins. The HPLC of oxidized C. neoformans melanin revealed PTCA and TDCA peaks (Fig. 2d) and the presence of these compounds was confirmed by matrix assisted laser desorption/ionization time of flight mass spectrometry (MALDI-TOF). The ratio of PTCA to TDCA was 47.7, which indicates that DHICA subunits predominate in $C$. neoformans melanin. Melanins produced by two different intrinsically melanized fungi Cladosporium sphaerospermum (Fig. 2e and Fig. 3) and by Wangiella dermatitidis (Fig. 2f) were chemically more diverse than C. neoformans melanin, revealing also the peaks assigned to PDCA and peaks at 9-10 min which may be attributed to the small amounts of oxidized 1,8-dihydroxynaphthalene (DHN) melanin.

Electron spin resonance spectroscopy (ESR) of melanized fungi showed the presence a stable free radical population (Fig. $2 \mathrm{~g}-\mathrm{i}$ and Fig. 4) in each of the above fungi, a distinguishing characteristic of melanin [26]. One important indication of melanin interaction with ionizing radiation was a large change in ESR signal of $C$. neoformans dry melanin "ghosts" after they were subjected to $0.3 \mathrm{kGy}$ irradiation and subsequently suspended in water (Fig. $2 \mathrm{~h}$ and $i$, respectively).

\section{Exposure to ionizing radiation and other forms of electromagnetic radiation increases electron transfer properties of melanin}

To quantify the effects of ionizing radiation and other forms of electromagnetic radiation on the electron transfer properties of melanin - we irradiated dry C. neoformans melanin for 20 and $40 \mathrm{~min}$ with $14 \mathrm{~Gy} / \mathrm{min}$ from a ${ }^{137} \mathrm{Cs}$ source and measured its electron transfer properties in the coupled oxidation of $\mathrm{NADH}$ and reduction of ferricyanide. In this system, melanin acts as an electron-transfer agent [27], however, the effects of electromagnetic radiation on melanin electron-transfer properties are unknown. Irradiation of melanin for $20 \mathrm{~min}$ increased the velocity of the NADH/ ferricyanide coupled reaction 3-fold in comparison to that measured for non-irradiated melanin, while $40 \mathrm{~min}$ irradiation had an even larger effect, causing a 4-fold increase in velocity (Table 1). When we investigated the influence of other, non-ionizing forms of radiation across the electromagnetic spectrum - heat (infrared radiation), visible light and UV light on the electron-transfer properties of melanin in $\mathrm{NADH} /$ ferricyanide coupled reaction - we found that each of these types of radiation increased the ability of melanin to transfer electrons (Table 2). Interestingly, the increase in the electron-transfer properties of melanin was independent of the energy of the incident photons (Table 2).

\section{Metabolic activity of melanized and non-melanized cells in the presence of electromagnetic radiation}

We investigated whether the changes in electron transfer properties of melanin post exposure to ionizing radiation (highenergy photons, see Table 2) may also be observed in melanized cells exposed to ionizing radiation. The metabolic activity of $C$. neoformans cells was evaluated with 2,3-bis(2-methoxy-4-nitro-5sulfophenyl)-5-[(phenylamino) carbonyl]-2H-tetrazolium hydroxide (XTT assay) [28] and 2-(4,5-dimethyl-2-thiazolyl)-3,5-diphenyl-2H-tetrazolium bromide (MTT assay). The use of XTT and MTT assays in parallel can help to define the location of the melanin-mediated electron transfer in the cells since positively charged MTT is taken into the cells via the plasma membrane potential and is reduced intracellularly; while the negatively charged XTT is largely cell-impermeable and its reduction occurs extracellularly, at the cell surface [29]. The melanized and nonmelanized C. neoformans cells were exposed to ionizing radiation in the dark at $22^{\circ} \mathrm{C}$ overnight. The irradiation was performed in a constant field of $0.05 \mathrm{mGy} / \mathrm{hr}$, a non-fungicidal radiation dose that is comparable to the doses inside the Chernobyl reactor [6]. Following exposure to radiation, the XTT or MTT reagents were added to the samples and absorbance was measured at 492 or $550 \mathrm{~nm}$, respectively. The XTT assay showed significant increase in electron-transfer events in the irradiated melanized cells in comparison with non-irradiated melanized or irradiated nonmelanized cells (Fig. 5a). Increased absorbance at $492 \mathrm{~nm}$ was also observed for dead (heat killed) melanized cells in comparison to non-melanized ones, showing that melanin can reduce XTT reagent by itself (Fig 5a). Irradiation of dead cells caused significant increase in the XTT reduction, thus confirming our hypothesis that radiation enhances electron-transfer properties of melanin. In contrast, there was no difference between the irradiated and nonirradiated melanized and non-melanized cells subjected to MTT assay (Fig. 5b). The difference between the MTT and XTT assays may be explained by the occurrence of radiation-related melaninmediated electron transfer events near cell wall where melanin is located that led to higher XTT reduction in irradiated melanized samples. Interestingly, both irradiated and non-irradiated melanized cells showed higher activity by MTT assay than nonmelanized cells (Fig. 5a, b). Given that melanization is associated with reduced pore size that could reduce passive nutrient uptake [25] and that melanin is synthesized from highly reactive cytotoxic intermediates of the oxidation of L-Dopa - it is possible that melanization requires a higher metabolism for cell survival.

In another series of experiments, the melanized and nonmelanized cells were grown overnight in the dark at room temperature $\left(22^{\circ} \mathrm{C}\right)$ or $30^{\circ} \mathrm{C}$. Melanized cells demonstrated increased XTT reduction activity at both temperatures in comparison with non-melanized controls (Fig. 5c), and increasing the temperature to $30^{\circ} \mathrm{C}$ caused a statistically significant increase in XTT reduction in melanized cells $(\mathrm{P}<0.05)$ while a small decrease was observed for non-melanized cells. Overall, these experiments showed the increase in electron transfer properties of melanin in melanized cells post exposure to ionizing radiation and to less extent - to heat.

\section{lonizing radiation enhances growth and ${ }^{14} \mathrm{C}$-acetate uptake of melanized $C$. neoformans cells}

To expand the observations of the influence of irradiated melanin on the growth of melanized cells, we measured the growth of melanized and non-melanized C. neoformans cells supplied with limited nutrients and placed into the radiation flux. To maintain a steady population of melanized cells, we used the same H99 strain of C. neoformans as in XTT/MTT experiments since it is capable of making melanin when maintained with L-Dopa while its laccase disrupted $[\mathrm{Lac}(-)]$ mutant is incapable of melanization [30]. The cells were grown into stationary phase up to $30 \mathrm{hr}$. There were significantly more $(\mathrm{P}=0.006)$ CFUs for irradiated melanized wild type H99 samples at 18, 23 and $30 \mathrm{hr}$ than for 
a)<smiles></smiles>

b)

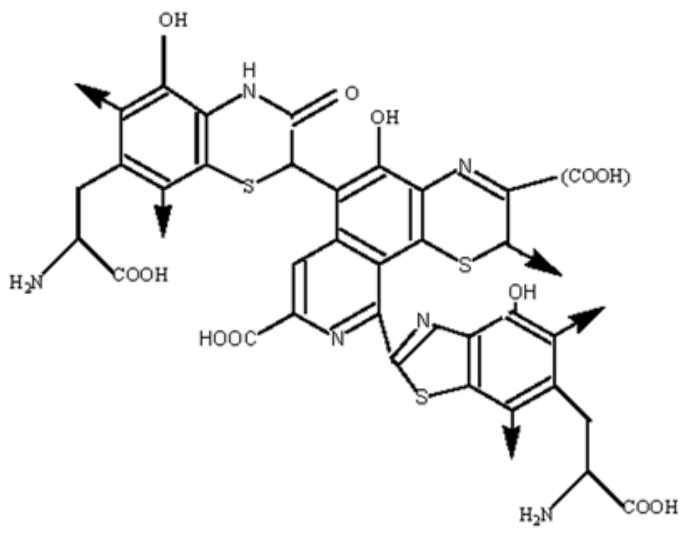

c)

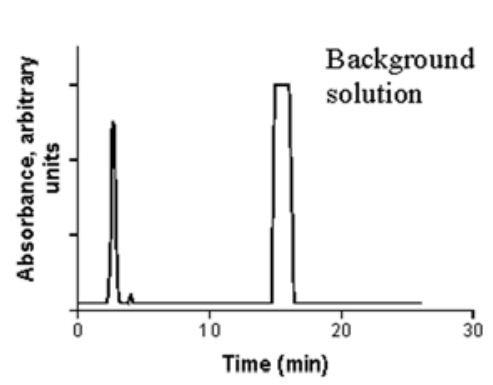

f)

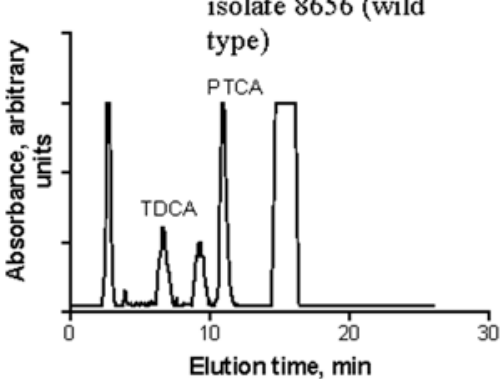

h)

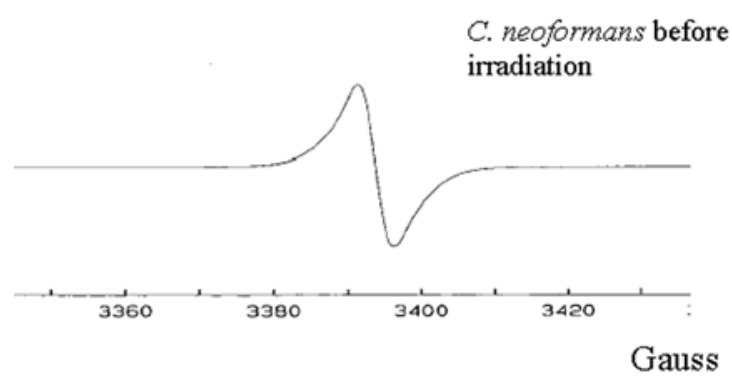

d)

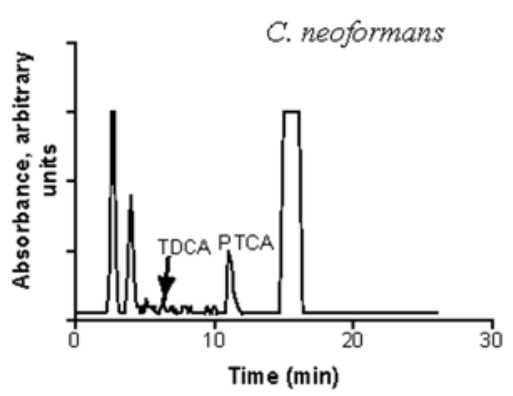

g)

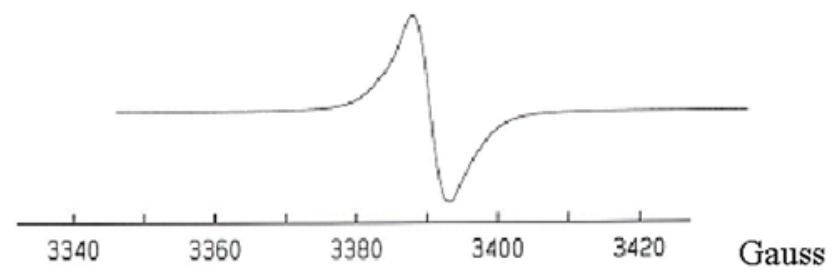

i)

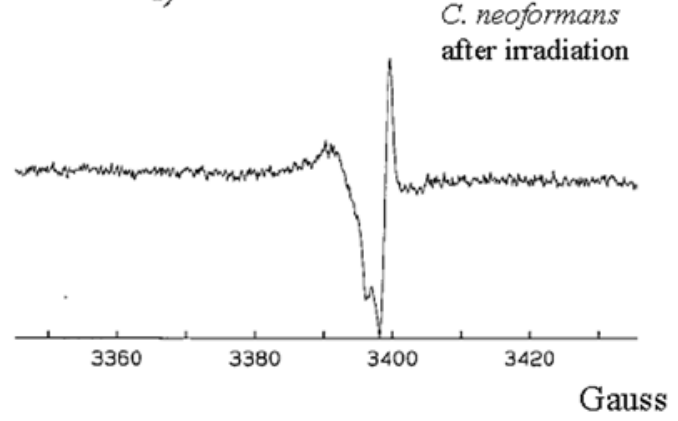

Figure 2. Chemical composition and paramagnetic properties of melanin: a) structure of eumelanin oligomer; b) structure of pheomelanin oligomer; ( $\mathrm{c}-\mathrm{f}) \mathrm{HPLC}$ of permanganate-oxidized melanins: c) chromatogram of background solution; d) C. neoformans; e) C. sphaerospermum grown on Sabaroud dextrose agar; f) W. dermatitidis isolate 8656 (wild type); (g-i) ESR spectra: g) W. dermatitidis isolate 8656; $\mathrm{h}$ ) C. neoformans before irradiation; i) C. neoformans after irradiation with $0.3 \mathrm{kGy}$ dose. PDCA - pyrrole-2,3-dicarboxylic acid; PTCA - pyrrole-2,3,5-tricarboxylic acid; TTCA - 1,3thiazole-2,4,5-tricarboxylic acid; TDCA - 1,3-thiazole-4,5-dicarboxylic acid. Absorption was monitored at $255 \mathrm{~nm}$ and displayed on a linear scale. ESR spectra were obtained by suspending "ghosts" in water except for ( $h$ ) which was performed in dry state. Ordinate in g-i is the derivative of the ESR absorption in arbitrary units.

doi:10.1371/journal.pone.0000457.g002 
a)

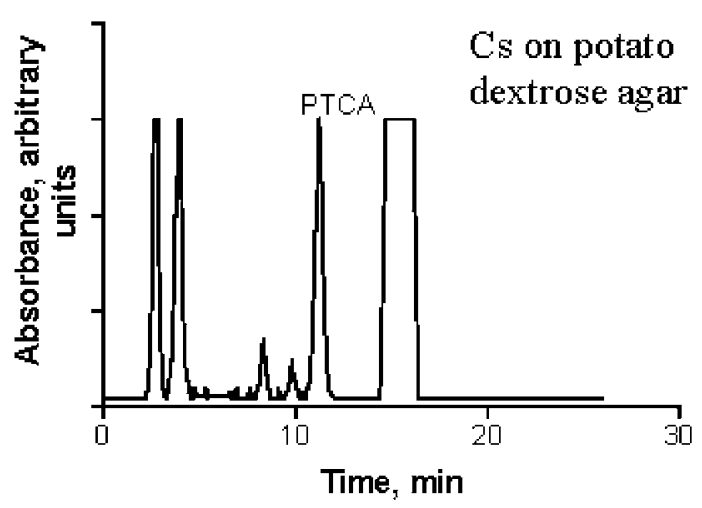

c)

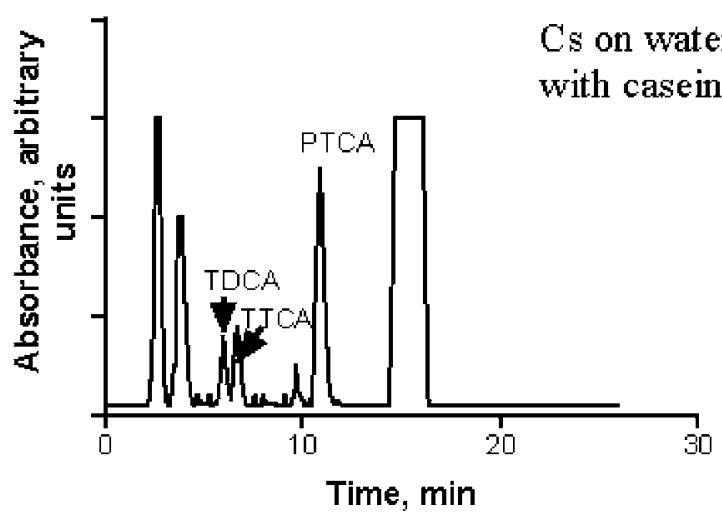

b)

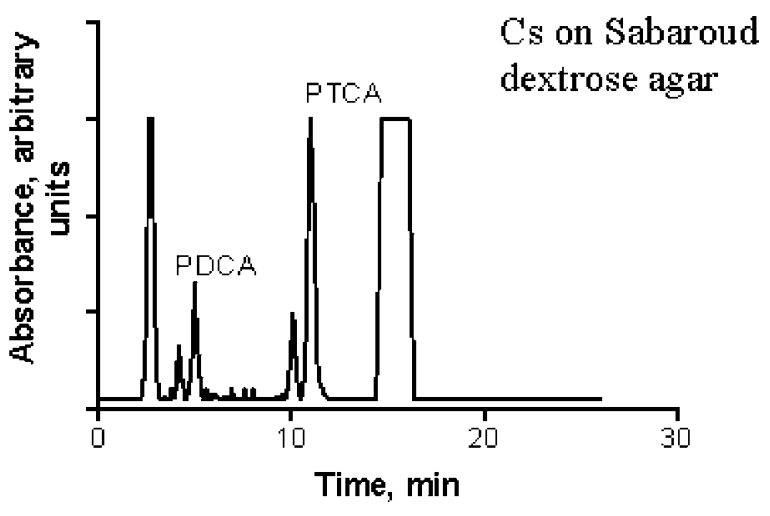

d)

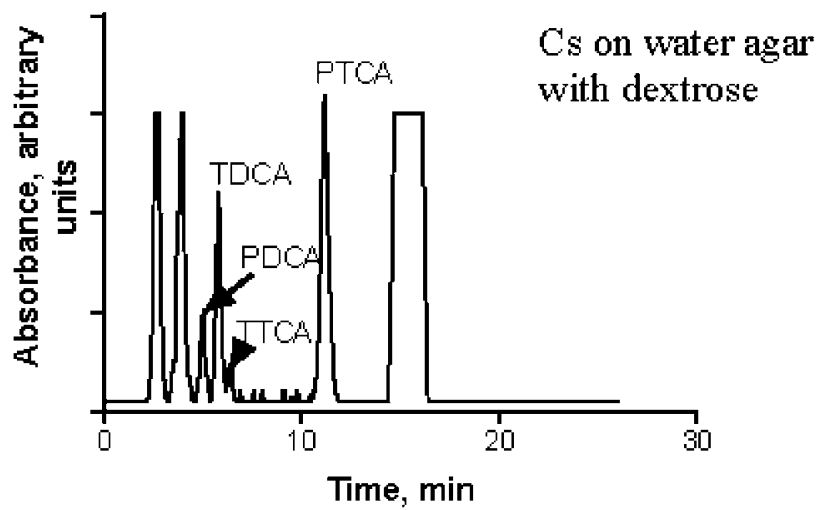

Figure 3. HPLC of melanin derived from C. sphaerospermum grown on different substrates: a) potato dextrose agar; b) Sabaroud dextrose agar; c) water agar with casein; d) water agar with dextrose. PDCA - pyrrole-2,3-dicarboxylic acid; PTCA - pyrrole-2,3,5-tricarboxylic acid; TTCA - 1,3thiazole-2,4,5-tricarboxylic acid; TDCA - 1,3-thiazole-4,5-dicarboxylic acid. Absorption was monitored at $255 \mathrm{~nm}$ and displayed on a linear scale. Cs - C. sphaerospermum.

doi:10.1371/journal.pone.0000457.g003

non-irradiated samples (Fig. 6a), while the difference in CFUs at $18 \mathrm{hr}$ between irradiated and non-irradiated Lac(-) mutant was not significant (Fig. 6b). Lac(-) without radiation in the presence of L-dopa grows better than wild type H99 (Fig. 6a and b). There was also a slight increase in the CFU's of irradiated Lac(-) cells at 23 and $30 \mathrm{hr}$. However, the crucial difference between the wild type H99 and Lac(-) cells is that the exposure to ionizing radiation produced approximately 2.5 times more CFUs in irradiated melanized cells than in non-irradiated melanized controls, while irradiation of Lac(-) cells resulted only in a 1.1-fold increase in CFUs (Fig. 6e). The dry weight measurements performed at $20 \mathrm{hr}$ showed a consistent and significant $6.5 \%$ increase for irradiated melanized samples $(P=0.02)$ while there was no difference in weight for the mutant strain after irradiation. The relatively small yet significant increase in dry weight of the melanized cells is a result of the high percentage of immature cells, with smaller capsules synthesized de novo in the dividing melanized irradiated cell culture. In this regard, a cell diameter that is one-half to one-third of that for a mature cell results in a 8- and 26-fold decrease in cell mass, respectively. Quantification of whole cell sizes using India ink stained cells showed that proximately $50 \%$ of melanized irradiated cells had volumes 2 times smaller than those in the irradiated Lac(-) mutant population (results not shown), accounting for the relatively small increase in the dry weight of the melanized H99 samples in comparison to their larger increase in CFUs.

To obtain additional evidence that exposure to ionizing radiation enhanced melanized cell growth, we measured the incorporation of a ${ }^{14} \mathrm{C}$-labeled carbon source (acetate) into melanized and non-melanized $C$. neoformans cells with and without radiation flux. In the photosynthesis field the incorporation of ${ }^{14} \mathrm{C}$ acetate in bacteria subjected to visible light is considered to be indicative of their photoheterotrophic capabilities [31]. We measured a lower absolute uptake of ${ }^{14} \mathrm{C}$-acetate by wild type H99 compared to Lac(-) cells (Fig. 6c,d). There was no incorporation of ${ }^{14} \mathrm{C}$-acetate into heat killed melanized or nonmelanized cells, which excludes the possibility that radiation promoted the passive absorption of ${ }^{14} \mathrm{C}$-acetate on melanin. Importantly, when melanized and non-melanized Lac(-) H99 cells were incubated with ${ }^{14} \mathrm{C}$-acetate with and without radiation there was almost 3 times more incorporation of ${ }^{14} \mathrm{C}$-acetate into 
a)
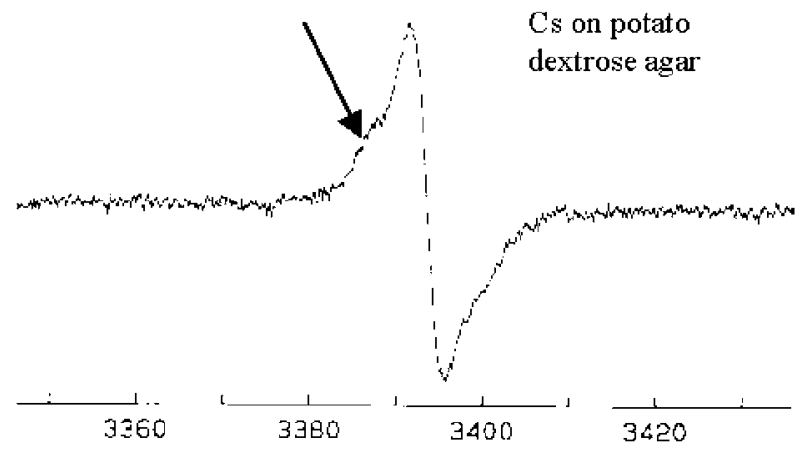

Gauss b)

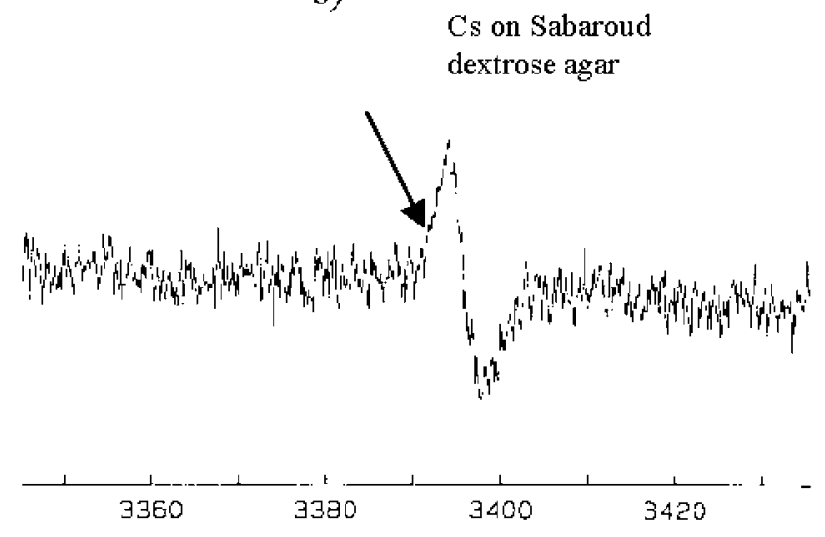

Gauss

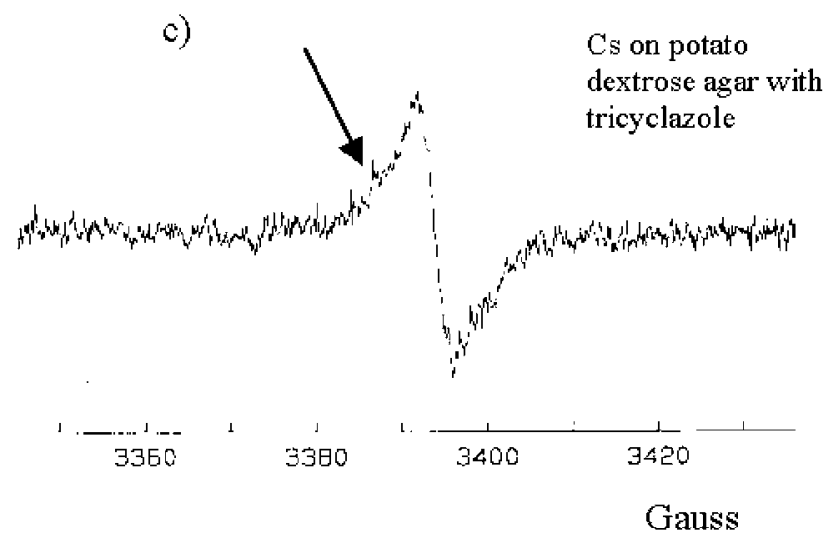

Figure 4. ESR spectra of melanin derived from C. sphaerospermum grown on different substrates: a) potato dextrose agar; b) Sabaroud dextrose agar; c) potato dextrose agar impregnated with $25 \mu \mathrm{g} / \mathrm{mL}$ tricyclazole. Differences in C. sphaerospermum ESR spectra in comparison with C. neoformans are marked with arrows. ESR spectra were obtained by suspending "ghosts" in water. Ordinate is the derivative of the ESR absorption in arbitrary units. Cs - C. sphaerospermum.

doi:10.1371/journal.pone.0000457.g004

irradiated melanized cells than into non-irradiated melanized cells, while the ratio of ${ }^{14} \mathrm{C}$-acetate incorporation into irradiated to nonirradiated Lac(-) cells was only slightly higher than 1 (Fig. 6c,d and e). Overall, these results demonstrate that the presence of melanin contributes to the enhancement of cellular growth upon exposure to ionizing radiation in conditions of limited nutrients.

\section{Intrinsically melanized fungi C. sphaerospermum} and $W$. dermatitidis manifested enhanced growth in radiation flux

To accrue additional data that ionizing radiation can promote enhanced growth of melanized fungi we extended our observations

: Table 1. NADH-ferricyanide-melanin reaction in presence of untreated and irradiated C. neoformans melanin

\begin{tabular}{|c|c|c|c|}
\hline \multirow{3}{*}{ Sample } & \multicolumn{3}{|l|}{ Reaction system } \\
\hline & \multirow{2}{*}{$\begin{array}{l}\text { Ferricyanide+melanin } \\
\text { Ferricyanide reduced }\end{array}$} & \multicolumn{2}{|c|}{ Ferricyanide+NADH+melanin } \\
\hline & & NADH oxidized & Ferricyanide reduced \\
\hline \multirow[t]{2}{*}{ Untreated melanin } & $40 \mathrm{nmol}$ & $37 \mathrm{nmol}$ & $75 \mathrm{nmol}$ \\
\hline & $\mathrm{V}^{1}=9 \mathrm{nmol} / \mathrm{min}$ & & $\mathrm{V}=30 \mathrm{nmol} / \mathrm{min}$ \\
\hline \multirow[t]{2}{*}{ Irradiated melanin, $20 \mathrm{~min}$} & $60 \mathrm{nmol}$ & $100 \mathrm{nmol}$ & $200 \mathrm{nmol}$ \\
\hline & $\mathrm{V}=13 \mathrm{nmol} / \mathrm{min}$ & & $\mathrm{V}=80 \mathrm{nmol} / \mathrm{min}$ \\
\hline \multirow[t]{2}{*}{ Irradiated melanin, $40 \mathrm{~min}$} & $170 \mathrm{nmol}$ & $150 \mathrm{nmol}$ & $300 \mathrm{nmol}$ \\
\hline & $\mathrm{V}=38 \mathrm{nmol} / \mathrm{min}$ & & $\mathrm{V}=120 \mathrm{nmol} / \mathrm{min}$ \\
\hline
\end{tabular}

${ }^{7} \mathrm{~V}$ - initial velocity is expressed in nanomoles of ferricyanide reduced per min. doi:10.1371/journal.pone.0000457.t001 
Table 2. Increase in electron-transfer properties of melanin in $\mathrm{NADH} /$ ferricyanide coupled reaction after exposure to different forms of electromagnetic radiation

\begin{tabular}{lll}
\hline Radiation type & Photon energy, eV & $\begin{array}{l}\text { Increase in initial velocity in } \\
\text { NADH/ferricyanide reaction }\end{array}$ \\
\hline $\begin{array}{l}\text { lonizing radiation } \\
\text { from 137-Cs source }\end{array}$ & 661,000 & 4.0 \\
UV, $254 \mathrm{~nm}$ & 4.7 & 3.9 \\
Visible light, $250 \mathrm{~W}$ & 3 & 4.0 \\
Heat, $75^{\circ} \mathrm{C}$ & 0.1 & 3.7 \\
photosynthesis & 3 & $\mathrm{~N} / \mathrm{A}$ \\
\hline
\end{tabular}

$50 \mu \mathrm{g}$ of $C$. neoformans melanin was used in the reactions; melanin was subjected to 40 min treatment, placed into dry ice following treatments and taken up in the ferricyanide solution immediately before measurements. To exclude contribution of heat component during irradiation of melanin with $250 \mathrm{~W}$ light, the samples were placed in $25^{\circ} \mathrm{C}$ water bath.

doi:10.1371/journal.pone.0000457.t002

to two intrinsically melanized fungal species. In contrast to $C$. neoformans which must be supplied with laccase substrate like LDopa for melanization - both C. sphaerospermum and W. dermatitidis synthesize melanin without the need for exogenous precursors. Initially we selected $C$. sphaerospermum because this fungus is a dominant species inhabiting the damaged reactor at Chernobyl [6]. C. sphaerospermum was placed in a constant radiation field of $0.05 \mathrm{mGy} / \mathrm{hr}$ and colony diameters were measured for 15 days. We supplemented water agar with minimal media containing sources of carbon and mineral salts, and, in one condition, - with a limited amount of sucrose (Fig.7). We observed melanin production by this fungus even when the amounts of nutrients and energy sources in the media were very low or absent (Fig. 1be). To evaluate the contribution of melanin to the enhanced growth in the radiation flux - we generated non-melanized cells by growing the fungus in the presence of tricyclazole, a specific inhibitor of pentaketide synthetic pathway of 1,8-dihydroxynaphthalene (DHN) melanin [22]. Exposure of melanized cells to radiation was associated with increased growth of colonies in all conditions. On agar with sucrose, the irradiated melanized colonies of $C$. sphaerospermum grew significantly more in regard to their volume and faster as shown by their radial growth rate than control melanized or control melanin-deficient ones (Fig. 7). Irradiated melanized colonies grew more than irradiated melanindeficient cells demonstrating that radiation is not inducing fungal agarase - an enzyme that breaks down agar into possible nutrients, or simply altering the agar to provide nutrients. The same trend was observed for cells grown without sucrose - the largest and fastest growing colonies were observed for irradiated melanized cells in comparison with the other 3 controls. All colonies grown without sucrose were smaller than those grown with this nutrient. The enhanced growth as a consequence of better survival of melanized fungi in radiation field in comparison with nonmelanized ones can be also ruled out by inherent radioresistance of fungi, as the doses delivered to C. sphaerospermum were less than $0.0001 \%$ of the fungicidal dose $[8,9]$. The conclusion from these experiments is that melanin was produced by fungi even when the amounts of nutrients and energy sources in the media were very low of absent; and the irradiated melanized cells experienced increased growth even in the conditions of starvation.

The C. sphaerospermum system had two limitations: 1) generation of non-melanized cells required tricyclazole, a compound that could arguably affect other metabolic processes; and 2) this fungus is a mold and its hyphal cells aggregated and this precluded a)

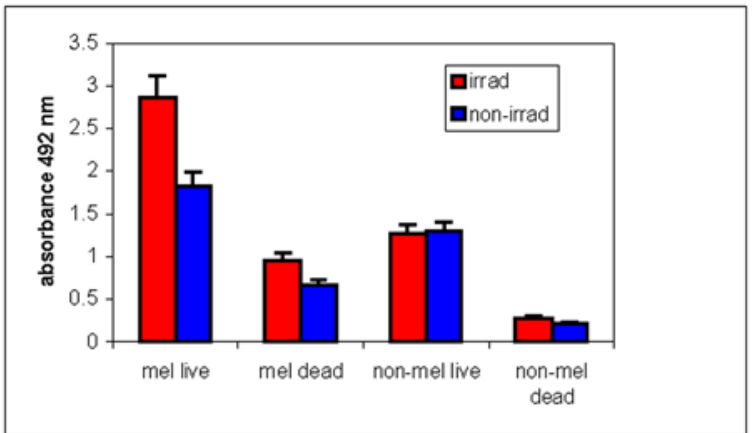

b)

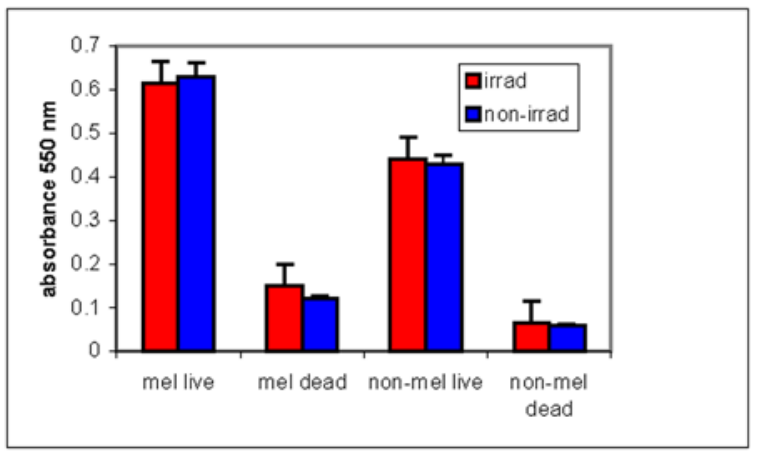

c)

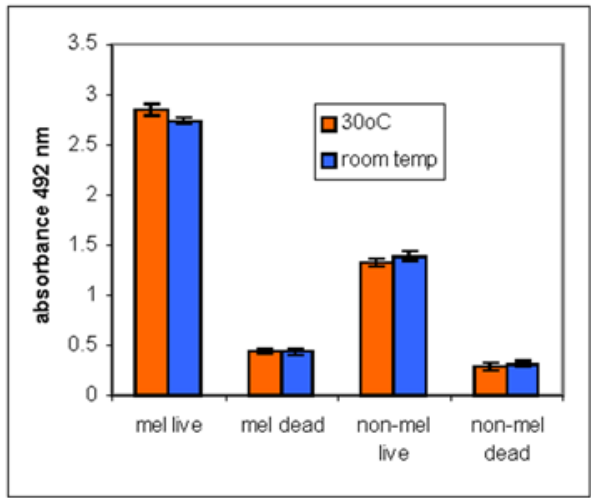

Figure 5. The influence of ionizing radiation or heat on the metabolic activity of melanized and non-melanized $C$. neoformans cells. a, b) irradiated and non-irradiated cells: a) XTT; b) MTT. c) XTT of cells grown at room temperature $\left(22^{\circ} \mathrm{C}\right)$ or at $30^{\circ} \mathrm{C}$. The cells were kept in the dark while being exposed to ionizing radiation or different temperatures. Following the exposure, XTT or MTT reagents were added to the samples and absorbance was measured at 492 or $550 \mathrm{~nm}$ for XTT and MTT, respectively.

doi:10.1371/journal.pone.0000457.g005

measuring growth by standard CFUs. Although the results showing larger colony radial growth were strongly suggestive of increased fungal mass, larger colonies could conceivably have resulted from differences in cellular packing or swelling. Consequently, we used a third organism to study the effect of irradiation on melanized fungal growth. Wangiella dermatitidis, an intrinsically melanized human pathogenic fungus that exists predominantly as a yeast form in vivo and at $37^{\circ} \mathrm{C}$, was selected for further study since an albino strain of $W$. dermatitidis (wdpks $1 \Delta-1$; lacking the polyketide synthase gene WdPKS1 responsible for generating melanin) and its complemented strain (wdpks14-1-501) recently 
a)

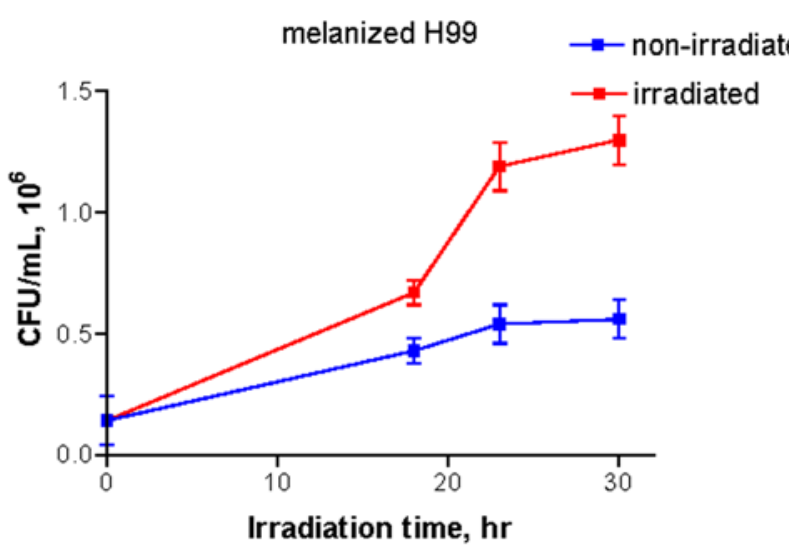

c)

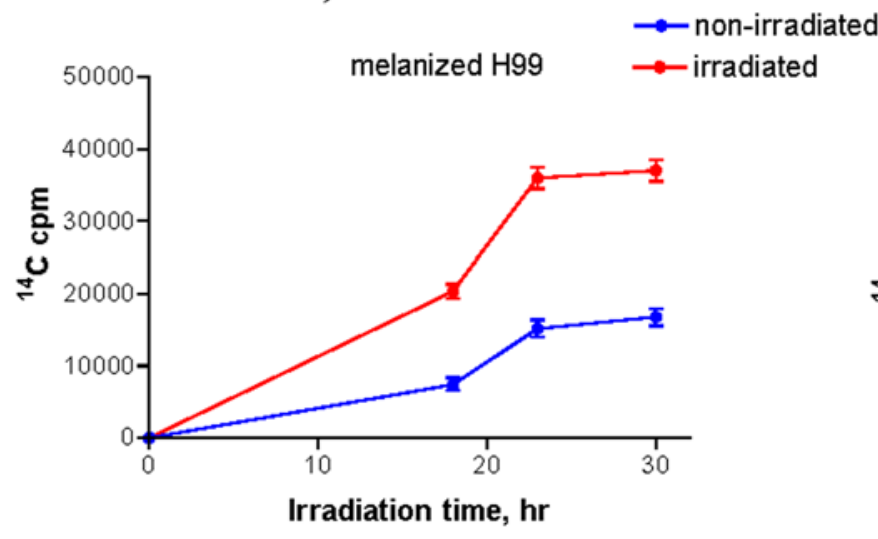

b)

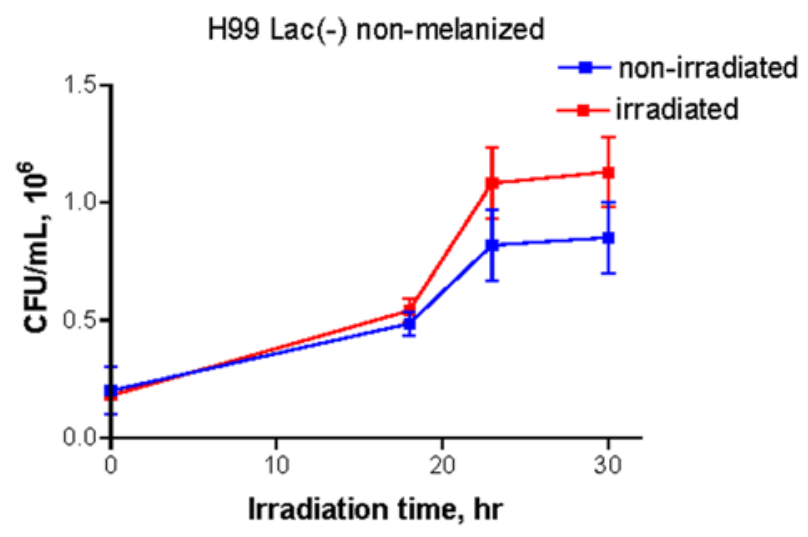

d)

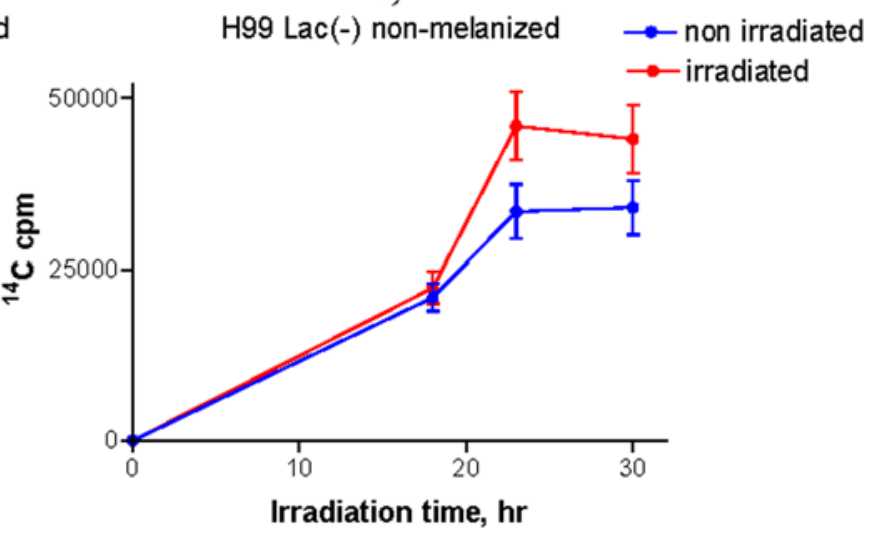

e)

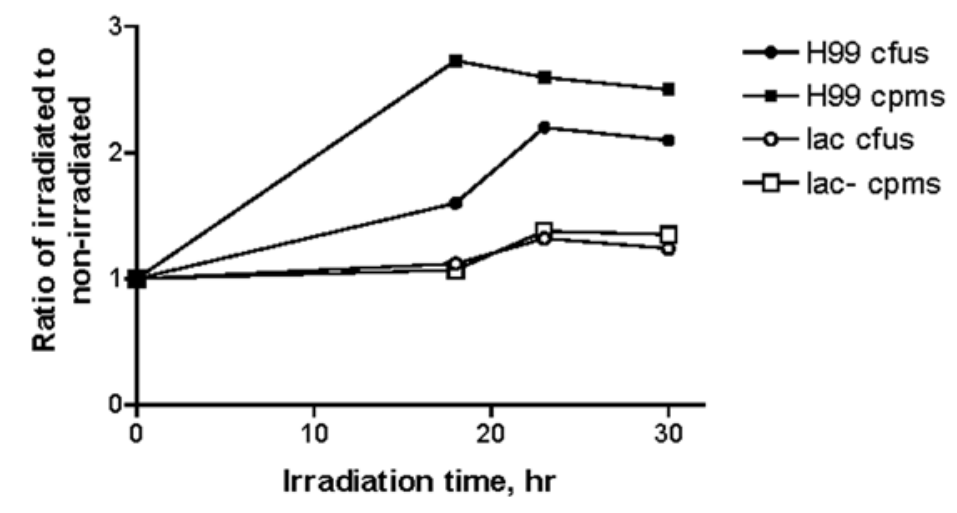

Figure 6. Growth and incorporation of ${ }^{14} \mathrm{C}$-acetate by melanized C. neoformans $\mathrm{H} 99$ cells and non-melanized Lac(-) H99 cells lacking the laccase enzyme under conditions of limited nutrients supply in a radiation field of $0.05 \mathrm{mGy} / \mathrm{hr}$ or at background radiation level. a) growth of melanized $\mathrm{H} 99$ cells; b) growth of non-melanized Lac(-) $\mathrm{H} 99$ cells; c) incorporation of ${ }^{14} \mathrm{C}$-acetate into melanized H99 cells; d) incorporation of ${ }^{14} \mathrm{C}$-acetate into non-melanized Lac(-) H99 cells; e) ratio of irradiated to non-irradiated cells CFUs and cpms ratios (normalized CFUs and cpms) for melanized H99 and non-melanized Lac(-) H99 cells.

doi:10.1371/journal.pone.0000457.g006

became available [23]. This fungus, which also produces fewer multicellular forms in vitro in comparison with C. sphaerospermum, allowed us to quantify the effect of radiation on cell growth by CFUs instead of measuring colony diameters.

Exposure of $W$. dermatitidis cells to ionizing radiation resulted in significantly more cells being produced, as measured by CFUs, for the melanized strains $(\mathrm{P}<0.01)$ than for the non-irradiated melanized control cells or the irradiated $w d p k s 1 \Delta-1$ albino mutant strain (Fig. 8a-c). At 16, 22 and $30 \mathrm{hrs}$ of irradiation the two melanin-containing strains of $W$. dermatitides had more colonies than the amelanotic mutant strain. As in the case of C. neoformans, some increased growth was observed in the irradiated albino 

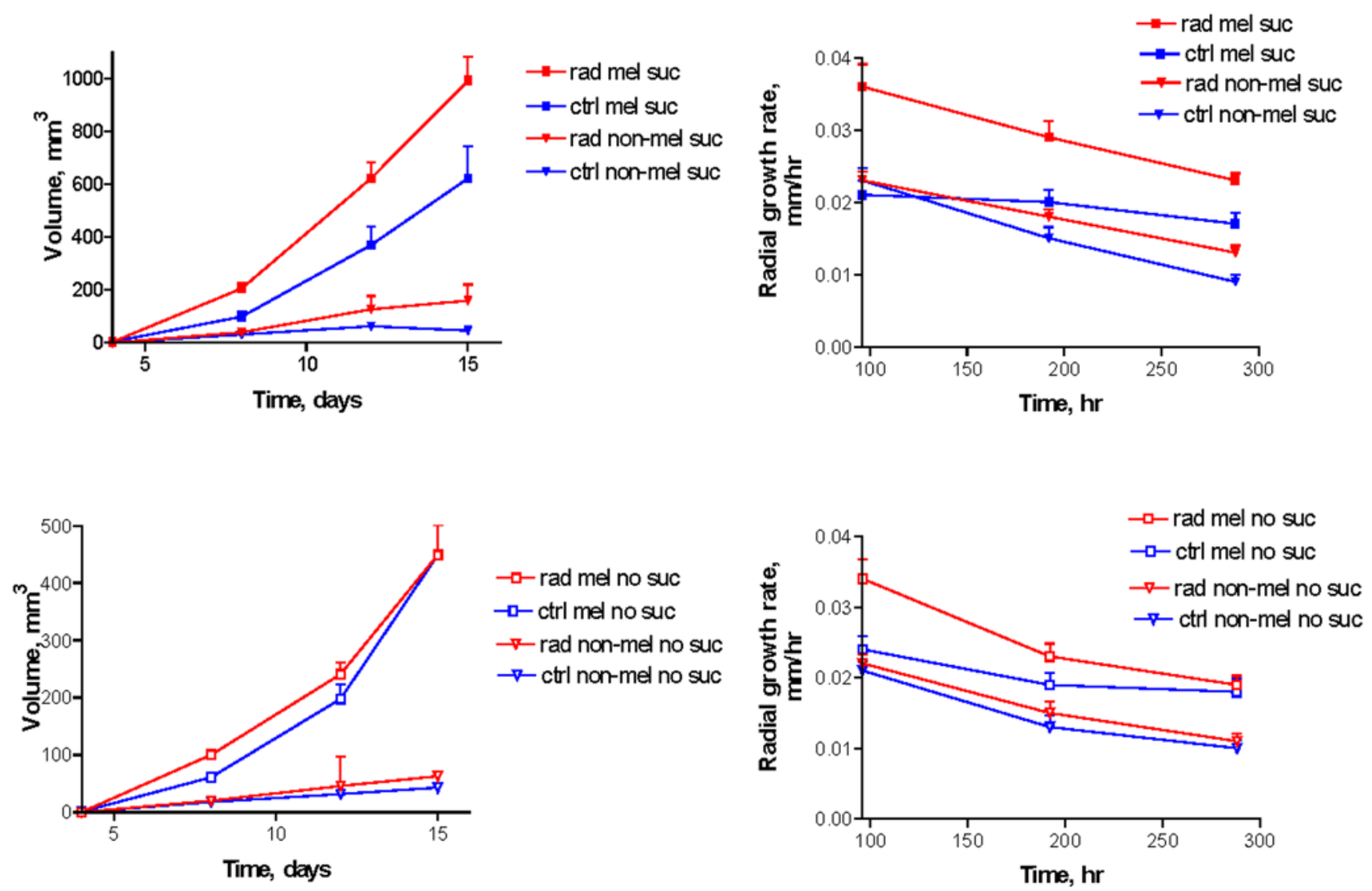

Figure 7. Survival of non-melanized and melanized C. sphaerospermum cells following exposure to external gamma rays: average volume (left side plates) and radial growth rate (right side plates) of melanized and melanin-deficient $C$. sphaerospermum colonies grown on agar plates with (top panels) or without (bottom panels) sucrose in a radiation field of $0.05 \mathrm{mGy} / \mathrm{hr}$ or at background radiation level (control). rad irradiated, ctrl - control, mel - melanized, suc- sucrose added. The volume of half-sphere was calculated as $V / 2=\pi / 12 \mathrm{~d}^{3}$. Radial linear growth rate of $C$. sphaerospermum colonies was calculated as $K=\left(R_{t}-R_{0}\right) /\left(t-t_{0}\right)$, where $K$ is radial linear growth rate, $m m / h r ; R_{t}$ and $R_{o}$ - colony radii at time $t$ and time $\mathrm{t}_{\mathrm{o}}$, respectively.

doi:10.1371/journal.pone.0000457.g007

mutant in comparison with non-irradiated albino cells at $16 \mathrm{hrs}$ (Fig. 8b). Wild type and complemented cells exposed to radiation manifested significantly shorter doubling times (Table 3) in comparison with non-irradiated controls while there was no statistical difference for the albino mutant. Dry weight experiments conducted for all three $W$. dermatitides strains irradiated for $20 \mathrm{hr}$ showed $8-10 \%(\mathrm{P}=0.02)$ increase in dry weight for melanized wild type and complemented strains in comparison with nonirradiated controls. As for C. neoformans - the lower percentage increase in dry weight in comparison with the percentage increase in CFUs (40 and 20\% for $20 \mathrm{hr}$ time point for wild type and complemented strains, respectively) can be explained by the fact that $50 \%$ of the cells in the melanized cultures were newly formed with volumes 2 times lower (results not shown) than that of the irradiated more mature albino cells.

\section{DISCUSSION}

To investigate the influence of ionizing radiation on the electrontransfer properties of melanin and on the growth of melanized fungi, we performed multiple physico-chemical tests and in vivo experiments with 3 genetically diverse fungi. HPLC results which reveal the chemical structure of melanin from different fungi are important for understanding the electronic properties of melanin. The number of electrons per gram is an important contributor to the attenuation properties of a material at the energy levels where the Compton effect predominates [32]. Compton scattering predominates for chemical elements with low atomic numbers such as $\mathrm{C}, \mathrm{N}, \mathrm{O}$ and $\mathrm{S}$ [32], which constitute melanin. In Compton scattering, transfer of a photon energy to matter occurs via a cascade of interactions, where the energy of the incident photon is transferred to high-energy electrons, and to secondary photons of progressively lower energy until the photoelectric effect takes place. Thus, the existence of structures composed of electronrich covalently linked aromatic motifs could explain radiation scattering properties of melanins. Furthermore, the higher number of electrons in oligomers of pheomelanin relative to eumelanin 388 versus 287 - could result in better scattering properties of pheomelanin.

The high-energy electrons generated by Compton scattering are ultimately responsible for the radiobiologic effects caused by gamma radiation by either direct interaction with DNA or through radiolysis of water in the cells, a process that results in the formation of reactive short-lived free radicals capable of damaging DNA. Stable free radicals in melanin may interact with these highenergy electrons and prevent them from entering a cell, thus enabling melanin to function as a radioprotector. The Compton electrons may then undergo secondary interactions with melanin molecules with their energy gradually lowered by melanin.

When performing experiments on measuring the growth and incorporation of ${ }^{14} \mathrm{C}$-acetate into irradiated and non-irradiated 
a)

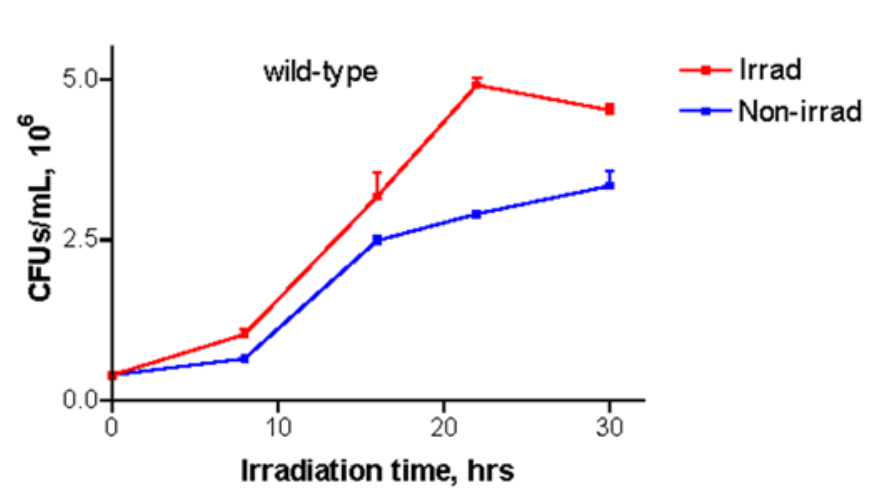

b)

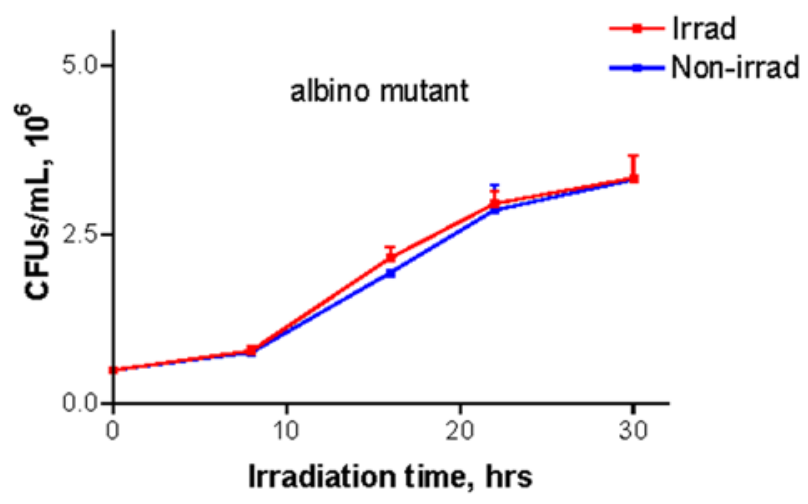

c)

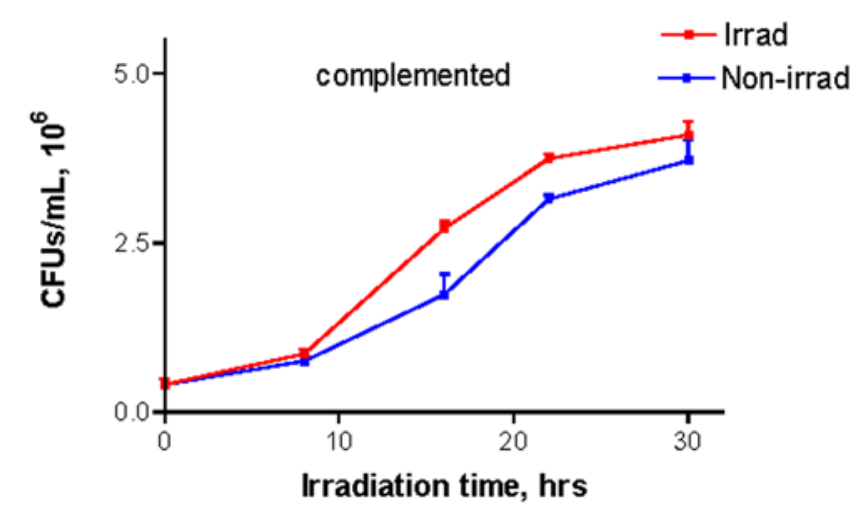

Figure 8. Growth of $W$. dermatitidis. a) wild type 8656 ; b) albino mutant $w d p k s 1 \Delta-1$ with a disrupted polyketide synthase gene; c) a strain complemented with wild type gene wdpks 1 . The cells were grown under conditions of limited nutrients in a radiation field of $0.05 \mathrm{mGy} / \mathrm{hr}$ or at background radiation level. The cells were exposed to radiation for various times and plated for CFUs on YPD. doi:10.1371/journal.pone.0000457.g008

melanized C. neoformans cells and its non-melanized Lac(-) mutant, we noted that non-irradiated Lac(-) cells grew better and incorporated more ${ }^{14} \mathrm{C}$-acetate than non-irradiated melanized cells (Fig. 6b,d). Although the basis for this difference is not understood it may be related to melanin limited porosity in the wild type melanized strain, since pore size decreases with culture age [25] and might reduce the availability of nutrients. Also, the process of

Table 3. Doubling times for $W$. dermatitidis grown in nutrientdeficient medium with and without radiation. The means and SEM of 4 experiments are presented.

\begin{tabular}{llll}
\hline \multirow{2}{*}{ Strain } & Doubling time, $\mathrm{hr}$ & & \\
\cline { 2 - 4 } & irradiated & control & P value $^{*}$ \\
\hline wild type & $6.5(0.1)$ & $7.4(0.2)$ & 0.02 \\
mutant & $9.8(1.0)$ & $10.8(1.8)$ & 0.7 \\
complemented & $6.8(0.1)$ & $7.3(0.1)$ & 0.01
\end{tabular}

*Wilcoxon non-parametric test for unpaired data was performed for each strain to compare doubling times for irradiated and control samples. Doubling time $=\ln 2 /\left(\left(\ln \left(A / A_{o}\right) / t\right)\right.$, where $A$-amount of cells at time $t, A_{o}-$ amount of cells at time 0 .

doi:10.1371/journal.pone.0000457.t003 melanization involves an oxidation reaction with generation of toxic intermediates which may impose a certain metabolic cost that could translate into slower in growth relative to $\mathrm{Lac}(-)$ cells. The slight increase in the CFU's and ${ }^{14} \mathrm{C}$-acetate incorporation of irradiated Lac(-) cells at 23 and $30 \mathrm{hr}$ is probably due to the well documented phenomenon that very low doses of ionizing radiation can stimulate cell proliferation $[33,34]$. However, the crucial difference between the wild type H99 and Lac(-) cells is that the exposure to ionizing radiation resulted in 2.5 times more CFUs and almost 3 times more incorporation of ${ }^{14} \mathrm{C}$-acetate in irradiated melanized cells than in non-irradiated melanized controls, while irradiation of Lac(-cells resulted only in a 1.1-fold increase in CFUs and ${ }^{14} \mathrm{C}$-acetate incorporation (Fig. 6e).

Melanins are unique biopolymers that protect living organisms against UV and ionizing radiation and extreme temperatures. The electronic complexity of melanins allows them to scatter/trap photons and electrons, which was evidenced in this study by the following observations: 1) changes the electronic structure of melanin post radiation exposure as measured by amplitude changes in the ESR signal; 2) electron transfer properties of melanin in the NADH oxidation/reduction reaction increased 4fold after melanin irradiation. The ability of radiation to preferentially enhance the growth of melanized fungi is implied by the following observations made in this study: melanized $C$. 
neoformans and $W$. dermatitidis cells exposed to levels of radiation approximately 500 times higher than background grew significantly faster as indicated by the presence of more CFUs, greater biomass as shown by dry weight measurements and/or relative incorporation of more ${ }^{14} \mathrm{C}$-acetate than non-irradiated melanized cells. Furthermore, comparative analysis of MTT/XTT reduction assays revealed that radiation-induced effects on the electron transfer properties of melanin were localized to the extracellular space thus establishing a spatial relationship between the site for electron-transfer events and the location of the melanin pigment. In addition, we recorded radiation-induced effects on the growth of melanized C. sphaerospermum cells under limited nutrients conditions. Hence, we observed that radiation increased the growth of melanized cells relative to non-melanized cells using three fungal species and four measures of cell growth.

The literature already contains some indirect evidence for the notion that radiation can enhance the growth of melanized microorganisms. For example, the melanotic fungus $C$. cladosporioides manifests radiotropism by growing in the direction of radioactive particles and this organism has become widely distributed in the areas surrounding Chernobyl since the nuclear accident in 1986 [7]. Both in the laboratory and in the field several other species of melanized fungi grew towards soil particles contaminated with different radionuclides, gradually engulfing and destroying those particles $[35,36]$. In addition, there are recent reports that certain life forms can utilize non-conventional forms of energy - microbes in geothermal vents at the bottom of the ocean can harvest thermal radiation as an energy source [37] while some microorganisms living in mines exploit energy from radiolysis of water [38]. On the basis of these precedents and the results of this study we cautiously suggest that the ability of melanin to capture electromagnetic radiation combined with its remarkable oxidation-reduction properties may confer upon melanotic organisms the ability to harness radiation for metabolic energy. The enhanced growth of melanotic fungi in conditions of radiation fluxes suggests the need for additional investigation to ascertain the mechanism for this effect.

\section{METHODS}

\section{Microorganisms}

American Type Culture Collection (ATCG, Rockville, MD) strain C. neoformans $\mathrm{H} 99$ and its laccase lacking mutant Lac(-) (kind gift from Dr. A. Idnurm, Duke University, NG) were used in all experiments. C. neoformans was grown in Sabouraud dextrose broth (Difco laboratories, Detroit, MI) for $24 \mathrm{hrs}$ at $30^{\circ} \mathrm{C}$ with constant shaking at $150 \mathrm{rpm}$. Melanized C. neoformans cells were generated by growing the fungus in minimal medium with $1 \mathrm{mM} \mathrm{3,4-}$ dihydroxyphenylalanine (L-dopa) for 5-10 days. C. sphaerospermum (ATCG, VA), an intrinsically melanized fungus, was grown on potato dextrose agar (Becton, Dickinson and Company) for 15 days. Approximately 1,000 C. sphaerospermum cells were plated on different media: water agar impregnated with minimal media (no glucose) and casein; agar dissolved in minimal media (no glucose) and $40 \mathrm{~g} / \mathrm{L}$ dextrose; potato dextrose agar (Becton, Dickinson and Company); potato dextrose agar impregnated with $25 \mathrm{ug} / \mathrm{mL}$ tricyclazole; and Sabaroud dextrose agar. The laboratory wild-type strain of intrinsically melanized W. dermatitidis 8656 \{ATCG 34100 [Exophiala dermatitidis CBS 525.76]\} a strain with a disrupted polyketide synthase gene $w d p k s 1 \Delta-1$, and its complemented isolate (wdpks14-1-501) were a kind gift from Dr. P. Szaniszlo (The University of Texas at Austin, Austin, TX). Routine propagation of these strains was in YPD [2\% peptone, 1\% Bacto Yeast extract, and 2\% dextrose] at $37^{\circ} \mathrm{C}$ with shaking at $150 \mathrm{rpm}$.

\section{Isolation and purification of fungal melanins}

Fungal cells were suspended in $1.0 \mathrm{M}$ sorbitol-0.1 M sodium citrate ( $\mathrm{pH}$ 5.5). Lysing enzymes from Trichoderma harzarium (Sigma Chemical Co.) were added to the suspension at $10 \mathrm{mg} / \mathrm{mL}$ and the suspensions were incubated overnight at $30^{\circ} \mathrm{C}$. Protoplasts were collected by centrifugation, and incubated in $4.0 \mathrm{M}$ guanidine thiocyanate overnight at room temperature. The resulting particulate material was collected by centrifugation, and Proteinase $\mathrm{K}(1.0 \mathrm{mg} / \mathrm{mL})$ in reaction buffer $(10.0 \mathrm{mM}$ tris, $1.0 \mathrm{mM} \mathrm{CaCl}_{2}, 0.5 \% \mathrm{SDS}$ ) was added to the particles followed by overnight incubation at $37^{\circ} \mathrm{C}$. The particles were boiled in $6.0 \mathrm{M}$ $\mathrm{HCl}$ for 1 hour. Finally, the resulting material ("ghosts") was washed with PBS, dialyzed against deionized water for 2 days and dried in air at $65^{\circ} \mathrm{C}$ overnight.

\section{Transmission electron microscopy (TEM)}

Samples were processed at the Analytical Imaging Facility, AECOM. The C. neoformans, C. sphaerospermum and W. dermatitidis "ghosts" or cells were frozen under high pressure using a Leica EMpact High Pressure Freezer (Leica Microsystems, Austria). Frozen samples were transferred to a Leica EM AFS Freeze Substitution Unit and freeze substituted in 1\% osmium tetroxide in acetone. They were brought from $-90^{\circ} \mathrm{C}$ to room temperature over 2-3 days, rinsed in acetone and embedded in Spurrs epoxy resin (Polysciences, Warrington, PA.). Ultrathin sections of 70$80 \mathrm{~nm}$ were cut on a Reichert Ultracut UCT, stained with uranyl acetate followed by lead citrate and viewed on a JEOL (Tokyo, Japan) 1200EX transmission electron microscope at $80 \mathrm{kV}$.

\section{Oxidation of melanins and HPLC of oxidized melanins}

The melanin "ghosts" were subjected to acidic permanganate oxidation as described in [18-21]. The pyrrole-2,3,5-tricarboxylic acid (PTCA), pyrrole-2,3-dicarboxylic acid (PDCA), 1,3-thiazole2,4,5-tricarboxylic acid (TTCA) and 1,3-thiazole-4,5-dicarboxylic acid (TDCA) used as standards were a kind gift from Dr. K. Wakamatsu of Fujita Health University of the Health Sciences, Toyoake, Japan. The oxidation products were analyzed by HPLC using a Shimadzu LC-600 liquid chromatograph, Hamilton PRP$1 \mathrm{C}_{18}$ column $(250 \times 4.1 \mathrm{~mm}$ dimensions, $7 \mu \mathrm{m}$ particle size $)$, and Shimadzu SPD-6AV UV detector. The mobile phase was $0.1 \%$ trifluoroacetic acid in water (solvent A) and $0.1 \%$ trifluoroacetic acid in acetonitrile (solvent $\mathrm{B}$ ). At $1.0 \mathrm{~mL} / \mathrm{min}$, the elution gradient was $(\min , \% \mathrm{~B}): 0,0 ; 1,0 ; 12,25 ; 14,25 ; 16,0$. The UV detector was set at a $255 \mathrm{~nm}$ absorbance.

\section{MALDI mass spectrometry}

The major peaks generated during chromatography of oxidized melanins were collected and analyzed by MALDI-TOF mass spectrometry in positive pressure mode on PE-Biosystems Mariner mass spectrometer. A peptide mixture with molecular weights of 1059.56, 1296.68 and 1672.95 in 2,5-dihydroxybenzoic acid matrix was used for calibration.

\section{Electron spin resonance spectroscopy (ESR)}

The ESR of melanin "ghosts" was performed on ER 200D EPR/ ENDOR spectrometer with ESP 300 upgrade (Brucker Instruments, Inc. Billerica, MA). ESR spectra were obtained by suspending "ghosts" in water. ESR spectra of C. neoformans "ghosts" were also obtained in dry state before irradiation with $0.3 \mathrm{kGy}$ and the "ghosts" were subsequently suspended in water and ESR was repeated. 


\section{$\mathrm{NADH}$-ferricyanide reaction in the presence of untreated and irradiated $C$. neoformans melanin}

The ability of melanin to oxidize or reduce NADH and ferricyanide was determined spectrophotometrically as in [27]. The absorbance of $\mathrm{NADH}$ was monitored at $340 \mathrm{~nm}$, of ferricyanide - at $420 \mathrm{~nm}$. Fifty $\mu \mathrm{g}$ of $C$. neoformans melanin was used in the reactions; dry melanin was subjected to 20 and $40 \mathrm{~min}$ irradiation with the $137-\mathrm{Cs}$ source at a dose rate of $14 \mathrm{~Gy} / \mathrm{min}$; put into dry ice following irradiation and taken up in the ferricyanide solution immediately before measurements.

\section{Determination of metabolic activity of melanized and non-melanized $C$. neoformans cells subjected to ionizing radiation or different temperatures by XTT and MTT assays}

Melanized and non-melanized C. neoformans cells were washed, suspended in PBS and their concentration was adjusted to $10^{8}$ per $\mathrm{mL}$. To account for the possibility of melanin itself changing the reaction through electron transfer or solubility/retention of formazan product [28] - the aliquots of both melanized and non-melanized cells were heat-killed at $65^{\circ} \mathrm{C}$ (water bath) for one hour and used as controls. $10^{7}$ cells were placed into the wells in 96 well plates, 5 wells per each condition. The plates were covered with foil to exclude any light effects and incubated overnight at room temperature $\left(22^{\circ} \mathrm{C}\right)$, at $30^{\circ} \mathrm{C}$, or at $22^{\circ} \mathrm{C}$ in a constant radiation field of $0.05 \mathrm{mGy} / \mathrm{hr}$. For XTT (2,3-bis(2-methoxy-4nitro-5-sulfophenyl)-5-[(phenylamino) carbonyl]-2H-tetrazolium hydroxide) assay $54 \mu \mathrm{L}(\mathrm{XTT}) /$ menadinone was added to each well, the plates were covered with foil, shaken for 2 minutes, and incubated at $37^{\circ} \mathrm{C}$ for $2 \mathrm{hrs}$. The absorbance was read at $492 \mathrm{~nm}$ (Labsystem Multiskan, Franklin, MA). For MTT (2-(4,5-dimethyl2-thiazolyl)-3,5-diphenyl-2H-tetrazolium bromide) assay, the MTT solution in PBS was added to the wells with the cells, so that the final MTT concentration became $0.5 \mathrm{mg} / \mathrm{mL}$. After incubation at $37^{\circ} \mathrm{C}$, the contents of the wells was spun down at 2,000 rpm, supernatant was discarded, followed by addition of $200 \mu \mathrm{l} 0.04 \mathrm{M} \mathrm{HCl}$ in absolute isopropanol to each sample. The samples were transferred into the 96-well plate and the absorbance was read at $550 \mathrm{~nm}$.

\section{Exposure of $C$. neoformans to ionizing radiation under limited nutrient conditions, ${ }^{14} \mathrm{C}$-acetate incorporation and dry weight measurements}

H99 wild type and Lac(-) mutant cells were grown as above. Melanization of $\mathrm{H} 99$ was achieved by incubation in $1 \mathrm{mM} \mathrm{L}-$ Dopa/minimal medium $(1 / 200)$ in the dark at $30^{\circ} \mathrm{C}$, at $150 \mathrm{rpm}$. The cells were washed with essential salts solution $\left(3 \mathrm{~g} / \mathrm{L} \mathrm{NaNO}_{3}\right.$, $1 \mathrm{~g} / \mathrm{L} \mathrm{K}_{2} \mathrm{HPO}_{4}, 1 \mathrm{~g} / \mathrm{L} \mathrm{MgSO}_{4} .7 \mathrm{H}_{2} \mathrm{O}, 0.5 \mathrm{~g} / \mathrm{L} \mathrm{KCl}, 0.003 \mathrm{~g} / \mathrm{L}$ thiamine, $5.3 \mathrm{~g} / \mathrm{L} \mathrm{NH}_{4} \mathrm{Cl}$ ), pelleted and taken up in $1 \mathrm{mM} \mathrm{Na}$ acetate solution in essential salts spiked with $0.1 \mu \mathrm{Ci} / \mathrm{mL}{ }^{14} \mathrm{C}$ acetate. The cell concentration was adjusted to $10^{5}$ cells $/ \mathrm{ml}, 1 \mathrm{~mL}$ samples of each strain were placed in $1.5 \mathrm{~mL}$ Eppendorf tubes $(4$ samples per time point) and subjected either to the background level of radiation or to a radiation field of $0.05 \mathrm{mGy} / \mathrm{hr}$ created by ${ }^{188} \mathrm{Re} /{ }^{188} \mathrm{~W}$ isotope generator for up to $30 \mathrm{hr}$ at $30^{\circ} \mathrm{C}$. The cell uptake of ${ }^{14} \mathrm{C}$-acetate was quantified by counting the tubes in a scintillation counter, spinning cells, separating supernatant and counting the cell pellet again. The cells were also plated for CFUs. For dry weight experiments $5 \mathrm{~mL}$ of cells at $4 \times 10^{7}$ cells $/ \mathrm{mL}$ cell density were irradiated for $20 \mathrm{hr}$ at $30^{\circ} \mathrm{C}$, filtered through preweighed $0.2 \mu$ filters, the filters were dried and weighed again.

\section{Exposure of C. sphaerospermum to ionizing radiation under limited nutrients conditions}

Melanized and non-melanized (tricyclazole-treated) C. sphaerospermum were grown on BBL Sabouraud dextrose agar for 15 days, harvested and plated on water agar prepared by mixing agar powder with minimal media lacking glucose. Four-sectional, $100 \times 15 \mathrm{~mm}$ dishes were used. Identical plates were made for irradiated and control samples. Five $\mathrm{mL}$ of the above agar was added to each of the left two sections of each plate. These sections were called "no sucrose" sections. Five mL volumes of sucrosecontaining agar (prepared by mixing agar powder with $100 \mathrm{mg} / \mathrm{L}$ sucrose as described in [6] and with minimal media lacking glucose) was added to the right two sections of each plate. Non-melanized $C$. sphaerospermum was added to the top compartments and melanized $C$. sphaerospermum was added to the bottom compartments of each plate. Agar in the top compartments where non-melanized C. sphaerospermum was plated contained $25 \mu \mathrm{g} / \mathrm{mL}$ tricyclazole to inhibit melanization. Approximately 20 cells per section were plated. All plates were prepared in duplicate. The plates were wrapped in foil and exposed continuously to $0.05 \mathrm{mGy} / \mathrm{hr}$ created by ${ }^{188} \mathrm{Re} /{ }^{188} \mathrm{~W}$ isotope generator for 15 days while control plates were exposed only to background radiation $\left(10^{-4} \mathrm{mGy} / \mathrm{hr}\right)$. The colonies were counted and measured daily.

\section{Exposure of $W$. dermatitidis to ionizing radiation under limited nutrients conditions and dry weight measurements}

Before radiation exposure, wild type, albino mutant and complemented strains of $W$. dermatitidis were cultured in the following manner using the modified procedure from [39]: frozen cells were diluted and cultured in $20 \mathrm{~mL}$ YPD at $37^{\circ} \mathrm{C}$ with shaking at $150 \mathrm{rpm}$ for $48 \mathrm{hrs}$, then diluted in YPD to $10^{6}$ cells/ $\mathrm{mL}$ and grown for another $48 \mathrm{hrs}$. At the end of the $2^{\text {nd }} 48 \mathrm{hr}$ period both wild type and complemented strains developed dark coloration while albino mutant cells were light yellow. The cells were again diluted to $10^{6}$ cells $/ \mathrm{mL}$ and cultured for $24 \mathrm{hrs}$, and this procedure was repeated once. Next, the cells were again diluted and grown for 24 hours in minimal chemical media $(3 \mathrm{~g} / \mathrm{L}$ $\mathrm{NaNO}_{3}, 1 \mathrm{~g} / \mathrm{L} \mathrm{K}_{2} \mathrm{HPO}_{4}, 1 \mathrm{~g} / \mathrm{L} \mathrm{MgSO}_{4} .7 \mathrm{H}_{2} \mathrm{O}, 0.5 \mathrm{~g} / \mathrm{L} \mathrm{KCl}$, $0.003 \mathrm{~g} / \mathrm{L}$ thiamine, $5.3 \mathrm{~g} / \mathrm{L} \mathrm{NH}_{4} \mathrm{Cl}$, $\mathrm{pH}$ of 6.5$)$ supplemented with $120 \mathrm{mg} / \mathrm{L}$ sucrose as a carbon source. The wild type and complemented strains maintained their dark color and the albino mutant remained light yellow. The cells were collected, washed, and diluted to $5 \times 10^{5}$ cells $/ \mathrm{mL}$ in the minimal medium. One $\mathrm{ml}$ aliquots in $1.5 \mathrm{ml}$ microfuge tubes were placed at $37^{\circ} \mathrm{C}$ in the dark without shaking, either in the cell incubator with the background level of radiation or in a radiation field of $0.05 \mathrm{mGy} / \mathrm{hr}$ created by ${ }^{188} \mathrm{Re} /{ }^{188} \mathrm{~W}$ isotope generator. For each time point, triplicate samples were used. After 16, 22 and $30 \mathrm{hrs}$ of exposure the cells were plated on YPD agar for 4 days at room temperature for determination of CFUs. The cells entered stationary phase around $30 \mathrm{hrs}$. For dry weight determinations, $20 \mathrm{~mL}$ of each strain in essential salts solution supplemented with $120 \mathrm{mg} / \mathrm{mL}$ sucrose at cell density of $10^{7}$ cell $/ \mathrm{mL}$ were irradiated for $20 \mathrm{hrs}$ or kept at background radiation level then filtered through pre-weighed $0.2 \mu$ filters that were dried and weighed again.

\section{Statistical analysis}

Wilcoxon non-parametric test for unpaired data was performed to analyze the differences in CFUs and ${ }^{14} \mathrm{C}$-acetate uptake. Differences were considered statistically significant when $\mathrm{P}$ values were $<0.05$. 


\section{ACKNOWLEDGMENTS}

The authors thank Dr. P.J. Szaniszlo (University of Texas, TX) for the kind gift of Wangiella dermatitidis and Dr. L. Day (New York University, NY) for advice on light scattering.

\section{REFERENCES}

1. Hill HZ (1992) The function of melanin or six blind people examine an elephant. Bioessays 14: 49-56.

2. Jacobson ES (2000) Pathogenic roles for fungal melanins. Clin. Microbiol. Rev. 13: 708-717.

3. Steenbergen JN, Shuman HA, Casadevall A (2001) Cryptococcus neoformans interactions with amoebae suggest an explanation for its virulence and intracellular pathogenic strategy in macrophages. Proc. Natl. Acad. Sci. USA. 98: 15245-15250.

4. Nosanchuk JD, Casadevall A (2003) The contribution of melanin to microbial pathogenesis. Cell. Microbiol. 5: 203-223.

5. Robinson CH (2001) Cold adaptation in Arctic and Antarctic fungi. New phytologist 151: 341-353

6. Wember VV, Zhdanova NN (2001) Peculiarities of linear growth of the melanincontaining fungi Cladosporium sphaerospermum Penz. and Alternaria alternata (Fr.) Keissler. Mikrobiol. Z. 63: 3-12.

7. Zhdanova NN, Tugay T, Dighton J, Zheltonozhsky V, McDermott P (2004) Ionizing radiation attracts soil fungi. Mycol Res. 108: 1089-1096.

8. Mirchink TG, Kashkina GB, Abaturov ID (1972) Resistance of fungi with different pigments to radiation. Mikrobiologiia 41: 83-86.

9. Saleh YG, Mayo MS, Ahearn DG (1988) Resistance of some common fungi to gamma irradiation. Appl. Environm. Microbiol. 54: 2134-2135.

10. Taylor TN, Hass H, Kerp H, Krings M, Hanlin RT (2005) Perithecial ascomycetes from the 400 million year old Rhynie chert: an example of ancestral polymorphism. Mycologia 97: 269-285.

11. Jansonius J, Kalgutkar RM (2000) Redescription of some fossil fungal spores. Palynology 24: 37-47.

12. Hulot G, Gallet Y (2003) Do superchrons occur without any palaeomagnetic warning? Earth Planetary Sci. Lett. 210: 191-201.

13. Davis M, Hut P, Muller RA (1985) Terrestrial catastrophism: Nemesis or Galaxy? Nature 313: 503.

14. Casadevall A (2005) Fungal virulence, vertebrate endothermy, and dinosaur extinction: is there a connection? Fungal Genet. Biol. 42: 98-106.

15. Redman RS, Sheehan KB, Stout RG, Rodriguez RJ, Henson JM (2002) Thermotolerance generated by plant/fungal symbiosis. Science 298: 1581-1583.

16. Nicolaus RA (1968) Melanins. Hermann, Paris

17. Wilczok T, Bilinska B, Buszman E, Kopera M (1984) Spectroscopic studies of chemically modified synthetic melanins. Arch. Biochem. Biophys. 231: 257-262.

18. Ito S, Fujita K (1985) Microanalysis of eumelanin and pheomelanin in hair and melanomas by chemical degradation and liquid chromatography. Anal. Biochem. 144: 527-536.

19. Wakamatsu K, Ito S (2002) Advanced chemical methods in melanin determination. Pigment Cell Res. 15: 174-183.

20. Garcia-Rivera J, Eisenman HC, Nosanchuk JD, Aisen P, Zaragoza O, et al. (2005) Comparative analysis of Cryptococcus neoformans acid-resistant particles generated from pigmented cells grown in different laccase substrates. Fungal Genet Biol. 42: 989-998.

21. Frases S, Chaskes S, Dadachova E, Casadevall A (2006) Induction by Klebsiella aerogenes of a melanin-like pigment in Cryptococcus neoformans. Appl Environ Microbiol. 72: 1542-1550.

\section{Author Contributions}

Conceived and designed the experiments: AC ED RB. Performed the experiments: RB AS PA JN XH TM. Analyzed the data: AC ED RB XH. Contributed reagents/materials/analysis tools: PA JN. Wrote the paper: AC ED. Other: Suggested the idea for the study: AC.

22. Starratt AN, Ross LM, Lazarovits G (2002) 1,8-Dihydroxynaphthalene monoglucoside, a new metabolite of Sclerotinia sclerotiorum, and the effect of tricyclazole on its production. Can. J. Microbiol. 48: 320-325.

23. Feng B, Wang X, Hauser M, Kaufmann S, Jentsch S, et al. (2001) Molecular cloning and characterization of WdPKS1, a gene involved in dihydroxynaphthalene melanin biosynthesis and virulence in Wangiella (Exophiala) dermatitidis. Infect Immun 69: 1781-1794.

24. Wang Y, Aisen P, Casadevall A (1996) Melanin, melanin "ghosts," and melanin composition in Cryptococcus neoformans. Infec. Immun. 64: 2420-2424.

25. Eisenman HC, Nosanchuk JD, Webber JB, Emerson RJ, Camesano TA, et al. (2005) Microstructure of cell wall-associated melanin in the human pathogenic fungus Cryptococcus neoformans. Biochemistry 44: 3683-3693.

26. Enochs WS, Nilges MJ, Swartz HM (1993) A standardized test for the identification and characterization of melanins using electron paramagnetic resonance (EPR) spectroscopy. Pigment Cell Res. 6: 91-99.

27. Gan EV, Haberman HF, Menon IA (1976) Electron transfer properties of melanin. Arch. Biochem. Biophys. 173: 666-672.

28. Kuhn DM, Balkis M, Chandra J, Mukherjee PK, Ghannoum MA (2003) Uses and limitations of the XTT assay in studies of Candida growth and metabolism. J Clin Microbiol. 41: 506-8.

29. Berridge MV, Herst PM, Tan AS (2005) Tetrazolium dyes as tools in cell biology: new insights into their cellular reduction. Biotechnol Annu Rev. 11: 127-52.

30. Hicks JK, D’Souza CA, Cox GM, Heitman J (2004) Cyclic AMP-dependent protein kinase catalytic subunits have divergent roles in virulence factor production in two varieties of the fungal pathogen Cryptococcus neoformans. Eukaryot Cell 3: 14-26.

31. Boomer SM, Pierson BK, Austinhirst R, Castenholz RW (2000) Characterization of novel bacteriochlorophyll-a-containing red filaments from alkaline hot springs in Yellowstone National Park. Arch Microbiol. 174: 152-161.

32. Sorenson JA, Phelps ME (1987) Physics in Nuclear Medicine. WB Saunders Company, Philadelphia.

33. Croute F, Soleilhavoup JP, Vidal S, Dupouy D, Planel H (1982) Paramecium tetraurelia growth simulation under low-level chronic irradiation. Investigations of a possible mechanism. Rad. Res. 92: 560-567.

34. Conter A, Dupouy D, Delteil C, Planel H (1986) Influence of very low doses of ionizing radiation on Synechococcus lividus metabolism during the initial growth phase. Arch Microbiol. 144: 286-290.

35. Zhdanova NN, Redchits TI, Lashko TN, Zheltonozhskii VA, Sadovnikov LV (2002) Destruction of radioactive particles by strains of Cladosporium cladosporoides (FRES.) de Vries. Mikrobiol Z. 64: 47-56.

36. Zhdanova NN, Lashko TN, Redchits TI, Vasilevskaia AI, Borisiuk LG, et al. (1991) The interaction of soil micromycetes with "hot" particles in a model system. Mikrobiol Zh. 53: 9-17.

37. Beatty JT, Overmann J, Lince MT, Manske AK, Lang AS, et al. (2005) An obligately photosynthetic bacterial anaerobe from a deep-sea hydrothermal vent. Proc. Nat. Acad. Sci. USA 102: 9306-9310.

38. Lin LH, Wang PL, Rumble D, Lippmann-Pipke J, Boice E, et al. (2006) Longterm sustainability of a high-energy, low-diversity crustal biome. Science. 314: $479-482$.

39. http://www.sbs.utexas.edu/mycology/sza_protocols_media.htm 